\title{
THE INFLUENCE OF SOLUTION CHOICE ON FLUID RESUSCITATION IN PA- TIENTS WITH SEPTIC SHOCK
}

\author{
Tinglan Zuo, S. Solyarik
}

The aim. Compare the hemodynamic effects and safety of infusion of the balanced crystalloid solution, sorbitol-based solution, and standard solution ( $0.9 \%$ sodium chloride).

Materials and methods. A prospective randomized clinical trial was carried out, the study included 92 adult patients, who had the active surgical infection, and were in a state of septic shock. A corresponding solution with a volume of $500 \mathrm{ml}$ was used for resuscitation. Hemodynamic and other clinical and laboratory parameters were monitored.

Results. There was no significant difference in mean arterial pressure (MAP) between the 3 groups before the 45th minute ( $p>0.05)$, from the 50th minute to 2 hours they were found only between the NS and Sorb groups ( $p<0.05)$. No statistically significant difference in heart rate (HR) was obtained in any measurement ( $p>0.05)$. Cardiac output (CO) and oxygen delivery $\left(\mathrm{DO}_{2}\right)$ did not differ until $35 \mathrm{~min}(p>0.05)$ and up to $40 \mathrm{~min}(p>0.05)$; after 40 min and $45 \mathrm{~min}$, a significant difference was also found between the Sorb and NS groups ( $p<0.05)$. After infusion of a sorbitol-containing solution and a balanced polyionic solution, the acid-base state of the blood significantly improved. The applied dose of the sorbitol-containing solution was safe for renal function and blood clotting in septic shock in this study. But the applied balanced polyionic solution may be associated with a decrease in the number of platelets. Daily changes by APACHE II scores in each group were not statistically significant. The difference in 7-day and 28-day mortality between groups was not statistically significant ( $p>0.05)$.

Conclusions. In our study, the balanced polyionic solution with $1.9 \%$ sodium lactate and $6 \%$ sorbitol was the most effective and safe infusion solution for the treatment of septic shock, it can be used as a supplement to balanced crystalloid solutions. When using a balanced polyionic solution (Ringer's acetate) with $0.07 \%$ L-malonic acid, the platelet count should be monitored more often

Keywords: sorbitol, balanced, crystalloid, Ringer's acetate, L-malonic acid, septic shock, monitoring, hemodynamics, safety, platelets

Copyright (C) 2021, Tinglan Zuo, S. Solyarik.

This is an open access article under the CC BY license (http://creativecommons.org/licenses/by/4.0).

\section{Introduction}

Infusion therapy is a key component of the treatment of septic shock [1]. Timely fluid therapy is critical for improving cardiac output, restoring oxygen delivery, and preventing multiple organ failure syndrome (MODS) in septic shock [2]. Therefore, infusion therapy is recommended as a first-line intervention for resuscitation of patients with this pathology [1]. Timely fluid resuscitation is associated with a decrease in hospital mortality [3], and delayed resuscitation is associated with a pronounced release of inflammatory mediators, mitochondrial dysfunction, and a worsening prognosis [4, 5]. When carrying out fluid resuscitation in septic shock, there is still no clear evidence of the advantage of any of the modern infusion solutions.

In the International Guidelines for Management of Sepsis and Septic Shock 2016 [1], the authors recommend crystalloid solutions for initial resuscitation and circulating blood volume (CBV) support, but no recommendation is given on which specific crystalloid solution should be used, as no direct comparison of isotonic saline and balanced saline in patients with sepsis. From colloidal solutions, it has been suggested to use albumin in addition to crystalloids for initial resuscitation and CBV support, provided that patients require significant amounts of crystalloids.
In Ukraine, a balanced polyionic solution with sodium lactate and sorbitol is widely used, which combines the properties of crystalloid and colloidal solutions. Due to its high hyperosmolarity, the drug promotes the flow of fluid from the intercellular space into the vascular bed, which improves microcirculation and tissue perfusion [6]. Due to the powerful specific osmo-diuretic effect of sorbitol, associated with the lack of natural mechanisms of reabsorption of polyhydric alcohols in the proximal renal tubules in humans, a pronounced diuretic effect is observed [7]. The lactate anion contained in the preparation helps to correct the acid-base state of the plasma, and also restores and stimulates the functions of the cells of the reticuloendothelial system, liver and kidneys [7]. All these qualities give grounds for using it for volumetric replacement therapy of various etiologies, such as hemorrhagic shock [8], polytrauma [6], acute pancreatitis [9], septic shock [10], anaphylactic shock [11].

Published studies have not sufficiently investigated the efficacy and safety of a balanced polyionic solution with sodium lactate and sorbitol in patients with sepsis and septic shock. Given the availability and widespread use of this drug in Ukraine, there is an urgent need to cover this topic and collect information on the safety and effectiveness of its use in patients with septic shock. 
The aim of the research - to compare the hemodynamic effects and safety of the infusion of balanced crystalloid solution, sorbitol-based solution and standard solution $(0.9 \%$ sodium chloride) in patients with septic shock.

\section{Materials and methods}

A prospective randomized controlled clinical study based on the Department of Anesthesiology and Intensive Care (DAIC) of Kiev City Clinical Hospital $(\mathrm{KCCH})$ No. 4 was carried out. The study complied with the principles of good clinical practice set out in the Declaration of Helsinki and informed consent was obtained from all patients. To conduct the study, permission was obtained from the Ethics Committee under $\mathrm{KCCH}$ No. 4 dated 01.06.2016. The study involved patients aged 27-92 years (mean age $65.3 \pm 15.2$ years), 38 men and 54 women hospitalized in DAIC with active surgical infection (intestinal obstruction, perforation of hollow organs, infected pancreatitis, abscess of parenchymal organs, gangrene of the lower extremities, peritonitis of other origin) and in a state of septic shock.

Septic shock was defined according to the criteria of The Third International Consensus Definitions for Sepsis and Septic Shock (Sepsis-3) [12] as sepsis (an increase in SOFA scores by 2 or more points) with a plasma lactate level of more than $2 \mathrm{mmol} / \mathrm{L}$ and a need for vasopressors to maintain mean arterial pressure (MAP) at $\geq 65 \mathrm{~mm} \mathrm{Hg}$.

The study did not include patients whose condition was recognized as incurable (terminal stage of cancer, total mesenteric thrombosis), as well as those who at the time of screening had already received a significant volume of infusion therapy $(>1000 \mathrm{ml}$ of solution for infusion) within the last 3 hours.

The randomization was done using the Random.org random number generator. Patients were randomized to one of the following groups:

- Sorb group (Sorb. - Sorbitol): patients who received an intravenous infusion of $500 \mathrm{ml}$ of balanced polion solution with $1.9 \%$ sodium lactate and $6 \%$ sorbitol;

- Bal group (Bal. - balanced crystalloids): patients receiving an intravenous infusion of $500 \mathrm{ml}$ of balanced polyionic solution (Ringer's acetate) with $0.07 \%$ L-malonic acid;

- NS group (NS - normal solution, control): patients received an intravenous infusion of $500 \mathrm{ml}$ of 0.9 $\%$ sodium chloride solution.

After screening patients and before starting infusion, baseline hemodynamic parameters (non-invasive blood pressure, pulse oximetry, heart rate (HR), electrocardiography), central venous pressure (CVP), plasma lactate level, acid-base state (ABS) and blood gases from the central vein, indicators of general and biochemical blood tests (bilirubin, creatinine, total protein, glucose, electrolytes, coagulogram and other indicators if necessary). Hemodynamic parameters such as cardiac output (CO), cardiac index (CI), stroke volume (SV), stroke index (SI) were monitored using an esophageal Doppler transducer and a corresponding monitor (CardioQ ODM+, Model No. 9051-6935, Deltex Medical, UK) and pulse wave velocity analysis (Bedside monitor with esC$\mathrm{CO}^{\mathrm{TM}}$ continuous cardiac output, Model: BSM-3562,
Nihon Kohden, Japan). The lactate content was determined using a photometric express system (Accutrend Plus, Roche, Germany). Also monitored: non-invasive blood pressure, pulse oximetry, HR, electrocardiography, central venous oxygen saturation $\left(\mathrm{ScvO}_{2}\right), \mathrm{CVP}$, the need for vasopressors. Body mass index (BMI) was calculated using the formula:

$\mathrm{BMI}=\mathrm{m} / \mathrm{h}^{2}$,

where: $\mathrm{m}$ - body weight in kilograms, $\mathrm{h}$ - height in meters.

The Acute Physiology And Chronic Health Evaluation II (APACHE II) scale was used to assess the severity of the patient's condition. The APACHE II and SOFA scores were calculated after a survey, physical and clinical laboratory examination of patients.

The APACHE II scale consists of three blocks:

1. Assessment of acute physiological changes (acute physiology score - APS): temperature, MAP, HR, respiratory rate, oxygenation, arterial blood $\mathrm{pH}$, concentration of sodium, potassium and creatinine in the blood, hematocrit, leukocytes, Glasgow score;

2. Age assessment.

3. Assessment of chronic diseases.

The SOFA (Sepsis-related Organ Failure Assessment) scale took into account the partial pressure of oxygen, the fraction of inhaled $\mathrm{O}_{2}$, the number of platelets, points on the Glasgow coma scale, the level of bilirubin, the degree of hypotension, and the level of creatinine.

Infusion of drugs in all groups was performed according to the principle of Goal-Directed therapy [13]: after the initial screening, a fast infusion test (within 15-18 minutes) of $500 \mathrm{ml}$ of the corresponding drug was performed and changes in hemodynamic parameters were recorded - an increase in cardiac output (CO), with growth $\geq 12 \%$, the test was considered positive, the infusion was continued with $500 \mathrm{ml}$ of $0.9 \%$ sodium chloride solution in each group, and the parameters were measured again. The cycle was repeated until the hemodynamic response to infusion was lost or the total infusion volume reached $20 \mathrm{ml} / \mathrm{kg}$ body weight for 2 hours. The average infusion volume was $1560 \pm 280 \mathrm{ml}$.

Repeated sampling of the general blood test (GBT) and biochemical blood test was performed on the 2nd day, the plasma lactate content and the coagulation system parameters were determined 2 hours after the start of fluid resuscitation, ABS and blood gases from the central vein were determined after 1 hour. The APACHE II and SOFA scores were repeated on day 2.

Patients were monitored by the research team until hospital discharge or death. Research endpoints:

1) the influence of the choice of solution for resuscitation on hemodynamics;

2) oxygen delivery index (DO2), oxygen delivery was calculated as $1.34 \times \mathrm{SaO}_{2} \times \mathrm{CO} \times \mathrm{Hb} / 100$, where 1.34 is the Hüfner constant, $\mathrm{SaO}_{2}$ is the saturation of arterial blood hemoglobin with oxygen ( $\%), \mathrm{Hb}$ is the hemoglobin concentration in the blood $\left(\mathrm{g} / \mathrm{L}^{6}\right)$; $\mathrm{ScvO}_{2}$

3 ) normalization of $\mathrm{pH}, \mathrm{BE}$ (base deficiency),

4) effect on kidney function (creatinine level);

5) influence on the coagulation function; 
6) change in the assessment of the severity of the patient's condition per day according to the APACHE II scale;

7) 7-day and 28-day mortality.

Statistical processing was performed in the SPSS Statistics 25.0.0 software environment (IBM Corporation, 2018).

To test the normal distribution of quantitative data: Shapiro-Wilk test. To assess the reliability of the obtained results, the following criteria were used: analysis of variance ANOVA (Leuven's test for testing the homogeneity of variance, for repeated multiple comparisons: Tukey's test, post hoc tests for homogeneous subgroups: Duncan's test), T-test of paired samples, Kruskal-Wallis test, Wilcoxon test, Criterion $\chi 2$.
In the work, the difference was considered statistically significant if the probability of false refutation of the null hypothesis was less than $5 \%(\mathrm{P}<0.05)$.

\section{Results}

The study included 92 patients, whose characteristics are presented in tab. 1. General characteristics of all 3 groups in terms of gender, age composition, height, weight, BMI, APACHE II scale, SOFA scale, and norepinephrine infusion rate, no statistically significant difference was found ( $\mathrm{p}>0.05)$.

In Fig. 1 is shown the distribution of patients according to the localization of surgical infection; there was no statistically significant difference between the groups, $\mathrm{p}>0.05$.

Table 1

Characteristics of groups Sorb, Bal and NS, M $\pm \mathrm{m}$

\begin{tabular}{|l|c|c|c|c|}
\hline \multicolumn{2}{|c|}{ Study groups } & Sorb $\mathrm{n}=32$ & Bal $\mathrm{n}=29$ & $\mathrm{NS} \mathrm{n}=31$ \\
\cline { 2 - 5 } \multicolumn{1}{|c|}{ Sex } & Male & $11(34.4 \%)$ & $16(55.2 \%)$ & $11(35.5 \%)$ \\
\hline Age (years) & $21(65.6 \%)$ & $13(44.8 \%)$ & $20(64.5 \%)$ \\
\hline Weight $(\mathrm{kg})$ & $27-92(67.4 \pm 3.0)$ & $31-82(60.2 \pm 2.7)$ & $31-89(66.6 \pm 3.0)$ \\
\hline Height $(\mathrm{cm})$ & $68.1 \pm 2.4$ & $70.2 \pm 2.6$ & $75.0 \pm 4.6$ \\
\hline BMI $\left(\mathrm{kg} / \mathrm{m}^{2}\right)$ & $169.69 \pm 1.4)$ & $170.81 \pm 1.8$ & $171.07 \pm 1.6$ \\
\hline Baseline APACHE II score (points) & $26.05 \pm 2.4$ & $25.58 \pm 2.6$ & $29.02 \pm 5.1$ \\
\hline Baseline SOFA score (points) & $14.64 \pm 0.9$ & $15.25 \pm 1.1$ & $14.43 \pm 1.1$ \\
\hline Baseline lactate level, $(\mathrm{mmol} / \mathrm{l})$ & $6.2 \pm 0.4$ & $6.88 \pm 0.8$ & $6.3 \pm 0.5$ \\
\hline Baseline MAP level, $\mathrm{mmHg}$ & $5.68 \pm 0.4$ & $5.50 \pm 0.5$ & $5.47 \pm 0.5$ \\
\hline Infusion rate of norepinephrine, $\mu \mathrm{g} / \mathrm{kg} / \mathrm{min}$ & $68.0 \pm 2.0$ & $68.0 \pm 1.0$ & $66.0 \pm 2.0$ \\
\hline
\end{tabular}

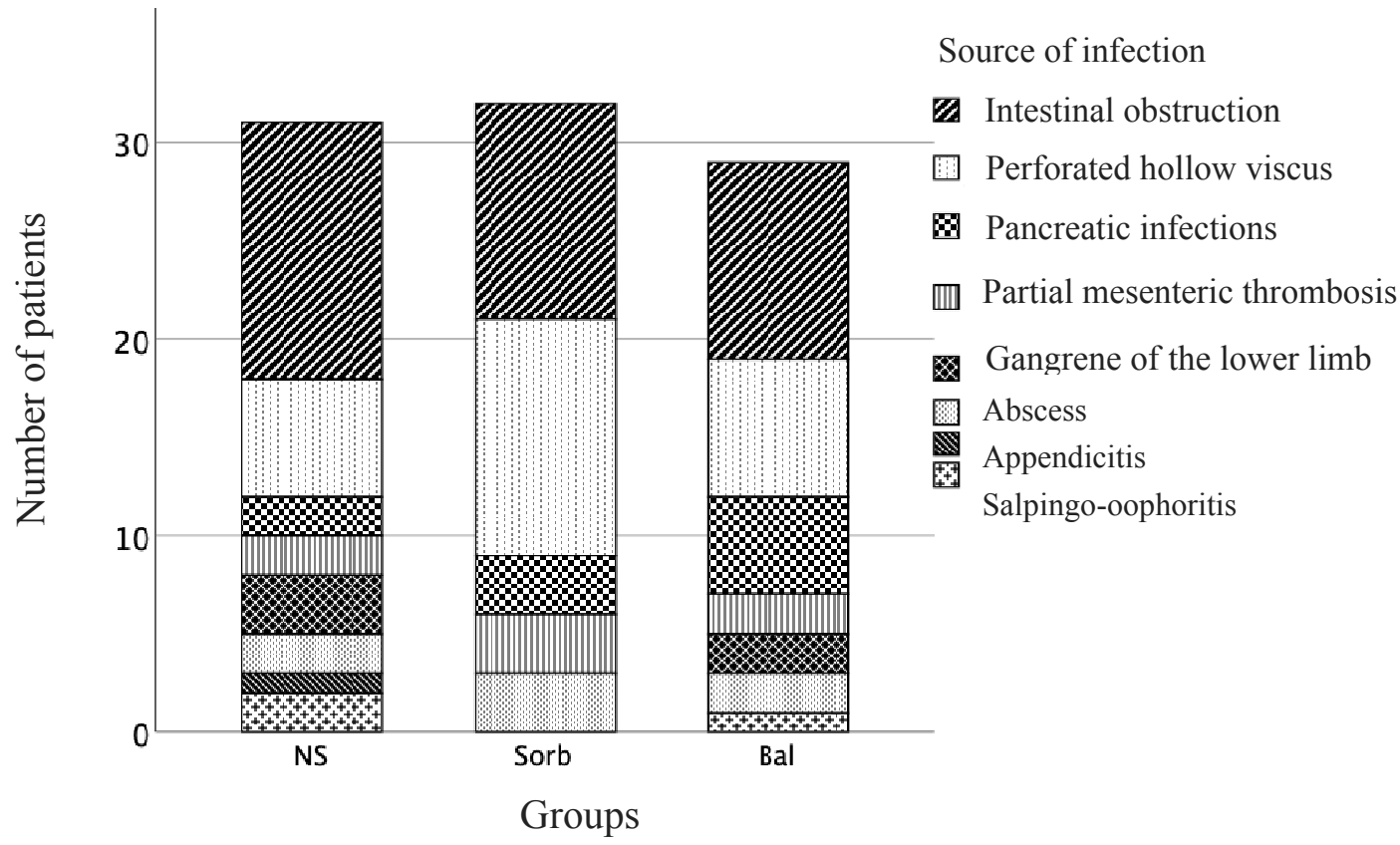

Fig.1. Diagram of distribution of patients in groups by source of surgical infection

Baseline MAP values were consistent with the definition of shock and amounted to $68.0 \pm 2.0 \mathrm{~mm} \mathrm{Hg}$ in the Sorb group, $68.0 \pm 1.0 \mathrm{~mm} \mathrm{Hg}$ in the Bal group and $66.0 \pm 2.0 \mathrm{~mm} \mathrm{Hg}$ in the NS group, there was no statistically significant difference between the groups ( $p>0.05)$.
After the start of the infusion of the study drugs, an increase in MAP occurred in all groups (Fig. 2). A significant increase in MAP was observed already at the 5th minute compared to the baseline, $\mathrm{MAP}_{\mathrm{Sorb}(0: 05)}=80.0 \pm 3.0 \mathrm{~mm}$ $\mathrm{Hg}, \quad \mathrm{p}_{\mathrm{Sorb}}<0.001, \quad \mathrm{MAP}_{\mathrm{Bal}(0: 05)}=79.0 \pm 3.0 \mathrm{~mm} \quad \mathrm{Hg}$, $\mathrm{p}_{\mathrm{Bal}}<0.001, \mathrm{MAP}_{\mathrm{NS}(0: 05)}=75.0 \pm 3.0 \mathrm{~mm} \mathrm{Hg}, \mathrm{p}_{\mathrm{NS}}<0.05$. 
The maximum increase in MAP in the Sorb group and Bal group was noted at the 15th minute and was $+26.05 \%$ and $+25.73 \%$ of the initial value $\left(\mathrm{p}_{\text {Sorb }}<0.001\right.$, $\left.\mathrm{p}_{\mathrm{Bal}}<0.001\right), \quad \mathrm{MAP}_{\mathrm{Sorb}(0: 15)}=85.0 \pm 3.0 \mathrm{~mm} \mathrm{Hg}$, $\mathrm{MAP}_{\mathrm{Bal}(0: 15)}=84.0 \pm 4.0 \mathrm{~mm} \mathrm{Hg}$. In the NS group, the maximum increase was noted at the 10th minute, $+26.84 \%$ $(\mathrm{p}<0.001), \mathrm{MAP}_{\mathrm{NS}(0: 10)}=83.0 \pm 4.0 \mathrm{~mm} \mathrm{Hg}$.

At 50 minutes, in the NS group, MAP did not differ from the baseline $(\mathrm{p}>0.05)$. After 1 hour 25 minutes, in the Bal group, MAP recovered to baseline $(\mathrm{p}>0.05)$. After $2 \mathrm{~h}$, the increase in MAP in the Sorb group remained $+11.99 \%$ of the initial value $(p<0.05)$, MAP $_{\text {Sorb (2:00) }}=76.0 \pm 2.0 \mathrm{~mm} \mathrm{Hg}$.

No significant difference was observed between the 3 groups until the 45 th minute $(\mathrm{p}>0.05)$, from the 50th minute to 2 hours, a significant difference was found only between the NS and Sorb groups $(p<0.05)$.

In all study groups at the start of the study, most of the patients were with tachycardia (Fig. 3). Average initial HR values were $105.0 \pm 5.0 \mathrm{bpm}$ in the Sorb group, in the Bal group $107.0 \pm 4.0 \mathrm{bpm}$, in the NS group $109 \pm 4.0 \mathrm{bpm}, \mathrm{p}>0.05$. After drug infusion, there was no significant change in HR in the Sorb group $(p>0.05)$. In contrast to the Sorb group, in the Bal group, after the drug infusion at the 5 th minute, there was immediately a significant slowdown in HR $-2.80 \% \quad(p<0.05)$, $\mathrm{HR}_{\mathrm{Bal}(0: 05)}=104.0 \pm 4.0 \mathrm{bpm}$, the maximum decrease in HR was observed at the 10th minute $-5.61 \%(p<0.05)$, $\mathrm{HR}_{\mathrm{Bal}(0: 10)}=101.0 \pm 4.0 \mathrm{bpm}$, reliable deceleration lasted until the 40th minute: $\operatorname{HR}_{\mathrm{Bal}(0: 40)}=103.0 \pm 4.0 \mathrm{bpm}$, $\mathrm{p}<0.05$, from the 45 th minute to 2 hours HR did not differ from the initial one $(p>0.05)$. In the NS group, only a significant HR deceleration was observed at the 10th minute of $-3.67 \%(\mathrm{p}<0.05), \mathrm{HR}_{\mathrm{NS}(0: 10)}=105.0 \pm 4.0 \mathrm{bpm}$, from the 15 th minute to 2 hours of HR not differed from the initial one $(p>0.05)$. No statistically significant difference between Sorb, Bal, and NS groups in HR was obtained in any measurement $(\mathrm{p}>0.05)$.

MAP (mm. Hg)

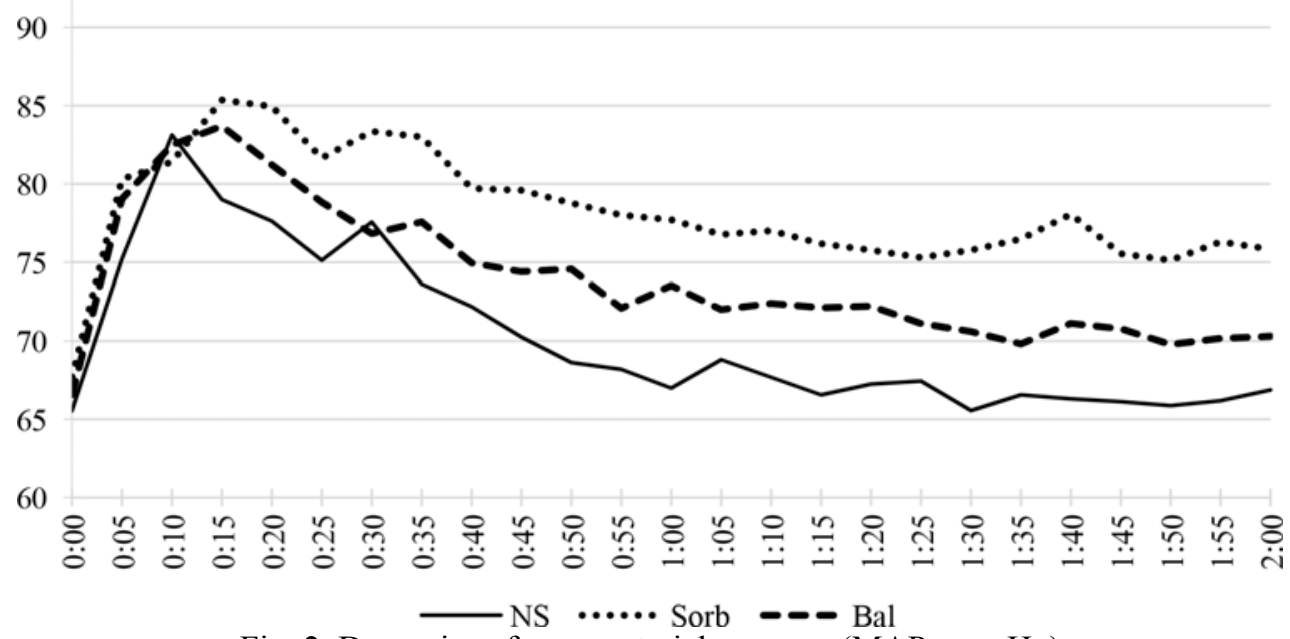

Fig. 2. Dynamics of mean arterial pressure (MAP, $\mathrm{mm} \mathrm{Hg}$ )

HR (per minute)

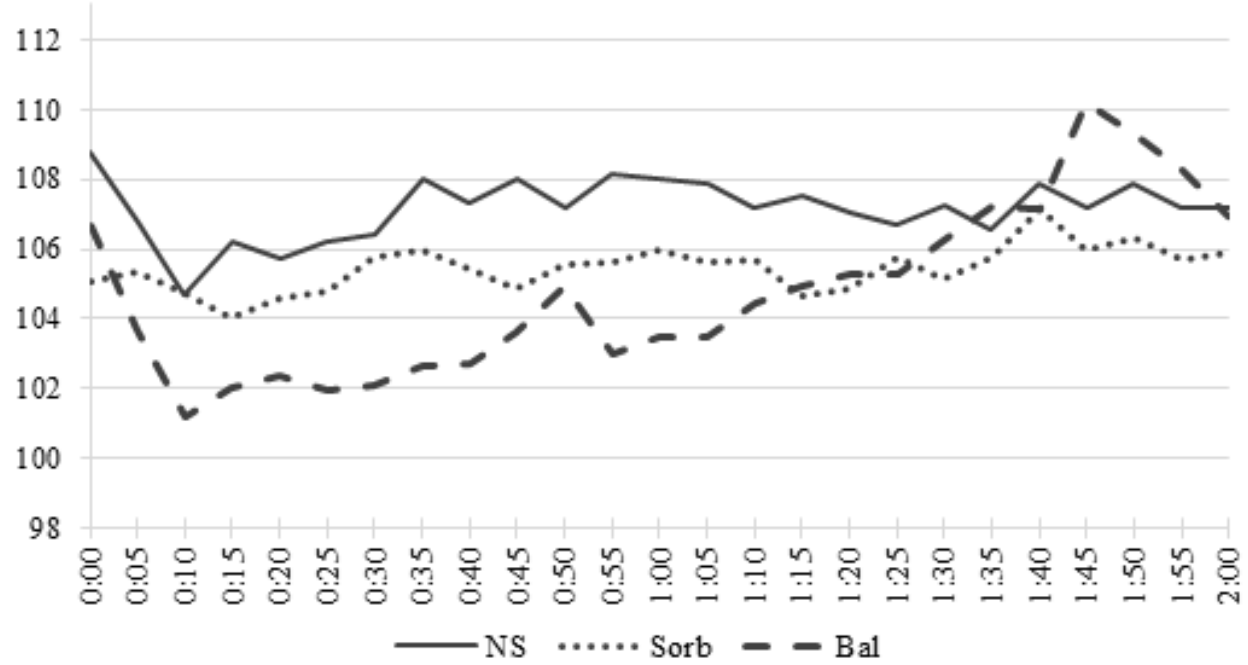

Fig. 3. Heart rate dynamics (HR, bpm) 
The average initial $\mathrm{CO}$ values were $4.40 \pm 0.36 \mathrm{~L} / \mathrm{min}$ in the Sorb group, $4.34 \pm 0.31 \mathrm{~L} / \mathrm{min}$ in the Bal group, $4.10 \pm 0.29 \mathrm{~L} / \mathrm{min}$ in the NS group, $\mathrm{p}>0.05$. After the start of the infusion of the study drugs, an increase in $\mathrm{CO}$ occurred in all groups (Fig. 4). In all groups, a significant increase in $\mathrm{CO}$ was observed immediately at the 5th minute, $\mathrm{CO}_{\mathrm{Sorb}(0: 05)}=4.85 \pm 0.33 \mathrm{~L} / \mathrm{min}$, $\mathrm{p}_{\mathrm{Sorb}}<0.05, \mathrm{CO}_{\mathrm{Bal}(0: 05)}=4.66 \pm 0.28 \mathrm{~L} / \mathrm{min}, \mathrm{p}_{\mathrm{Bal}}<0.05, \mathrm{CO}_{\mathrm{NS}}$ ${ }_{(0: 05)}=4.53 \pm 0.34 \mathrm{~L} / \mathrm{min}, \mathrm{p}_{\mathrm{NS}}<0.05$. The maximum increase in $\mathrm{CO}$ in the Sorb group was noted at 35 minutes and amounted to $+27.50 \%$ of the initial value $(\mathrm{p}<0.001)$, $\mathrm{CO}_{\mathrm{Sorb}(0: 35)}=5.61 \pm 0.39 \mathrm{~L} / \mathrm{min}$. In the Bal group, the maximum growth appeared at 1 hour 45 minutes, $+15.21 \%$ $(\mathrm{p}<0.05), \mathrm{CO}_{\mathrm{Bal}(1: 45)}=5.00 \pm 0.31 \mathrm{~L} / \mathrm{min}$. In the $\mathrm{NS}$ group, the maximum increase was noted at the 15 th minute, $+18.54 \%(\mathrm{p}<0.001), \mathrm{CO}_{\mathrm{NS}}(0: 15)=4.86 \pm 0.38 \mathrm{~L} / \mathrm{min}$. In the Sorb group, a significant increase continued until the end of the study, after 2 hours the increase in CO in the Sorb group was $+19.32 \%$ of the initial value $(p<0.001)$, $\mathrm{CO}_{\text {Sorb(2:00) }}=5.25 \pm 0.44 \mathrm{~L} / \mathrm{min}$. At 1 hour 50 mi-nutes, $\mathrm{CO}$ in the Bal group did not differ from baseline $(\mathrm{p}>0.05)$. In the NS group, $\mathrm{CO}$ at 45 minutes did not differ from the baseline $(\mathrm{p}>0.05)$.

No significant difference between the 3rd groups up to $35 \mathrm{~min}$ inclusive was observed in any case ( $\mathrm{p}>0.05$ ); from 40 min to 2 hours, a significant difference was found only between the Sorb and NS groups $(\mathrm{p}<0.05)$.

\section{Cardiac output (L / min)}

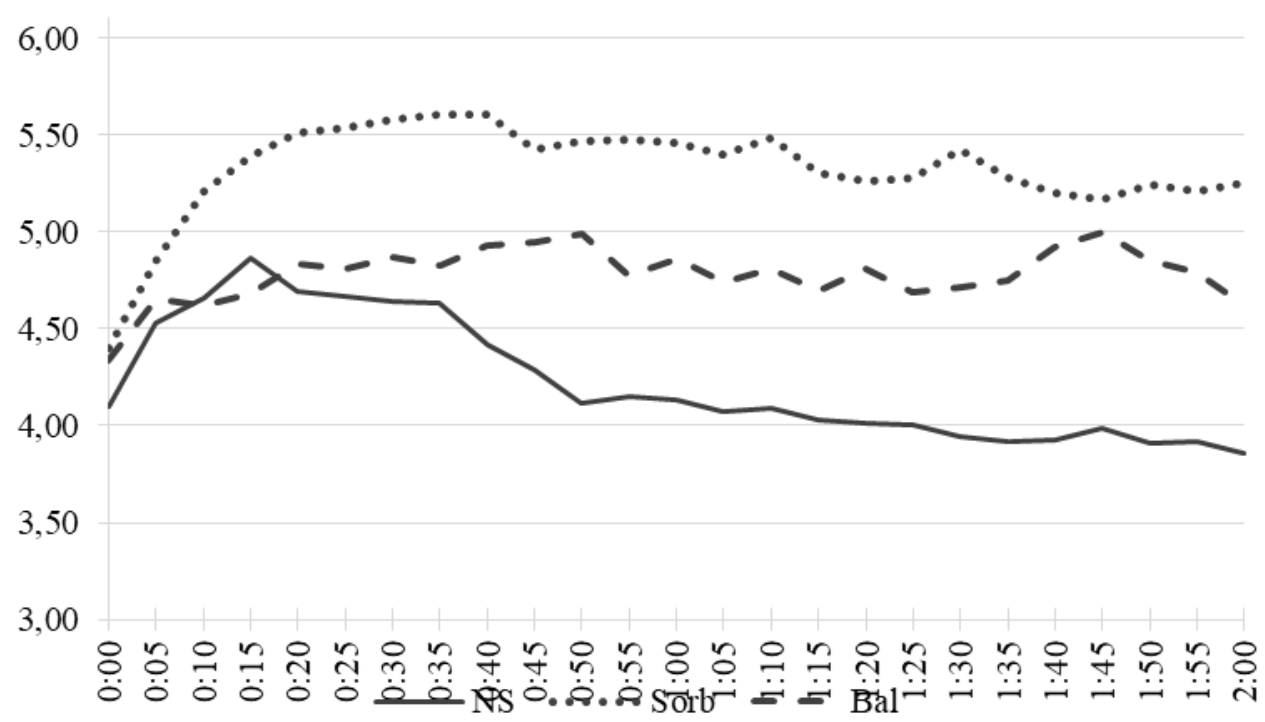

Fig. 4. Dynamics of cardiac output (CO, L/min)

The initial mean $\mathrm{DO}_{2}$ values in the Sorb group were $704.0 \pm 78.0 \mathrm{ml} / \mathrm{min}$, in the Bal group: $616.0 \pm$ $\pm 50.0 \mathrm{ml} / \mathrm{min}$, in the NS group: $631.0 \pm 64.0 \mathrm{ml} / \mathrm{min}$, significant no difference was found between groups $(\mathrm{p}>0.05)$.

The dynamics of $\mathrm{DO}_{2}$ (Fig. 5) after the start of the infusion of the study drugs changed significantly as a result of the infusion load. In all groups, a significant increase in $\mathrm{DO}_{2}$ was recorded from the 5 th minute, $\mathrm{DO}_{2 \operatorname{Sorb}(0: 05)}=770.0 \pm 75.0 \mathrm{ml} / \mathrm{min}, \quad \mathrm{p}_{\mathrm{Sorb}(0: 05)}<0.05$, $\mathrm{DO}_{2 \mathrm{Bal}(0: 05)}=662.0 \pm 46.0 \quad \mathrm{ml} / \mathrm{min}, \quad \mathrm{p}_{\mathrm{Bal}(0: 05)}<0.05$, $\mathrm{DO}_{2 \mathrm{NS}(0: 05)}=700.0 \pm 73.0 \mathrm{ml} / \mathrm{min}, \mathrm{p}_{\mathrm{NS}(0: 05)}<0.05$.

The maximum increase was observed in the Sorb group at 40 minutes $+25.57 \% \quad(\mathrm{p}<0.001)$, $\mathrm{DO}_{2} \operatorname{Sorb}(0: 40)=884.0 \pm 87.0 \mathrm{ml} / \mathrm{min}$, in the Bal group at 50 minutes $+16.07 \%(\mathrm{p}<0.05), \mathrm{DO}_{2}$ Bal(0:50) $=715.0 \pm$ $\pm 58.0 \mathrm{ml} / \mathrm{min}$, in the NS group at the 15 th minute $+18.70 \%$ $(\mathrm{p}<0.05), \mathrm{DO}_{2 \mathrm{NS}(0: 15)}=749.0 \pm 77.0 \mathrm{ml} / \mathrm{min}$.

In the Sorb group, all measurements were significantly higher than the initial ones $(p<0.05)$. After 2 hours, the increase in $\mathrm{DO}_{2}$ in the Sorb group remained $+18.32 \%$ of the initial value $(\mathrm{p}<0.001)$, $\mathrm{DO}_{2 \operatorname{Sorb}(2: 00)}=883.0 \pm 93.0 \mathrm{ml} / \mathrm{min}$.
A significant increase in $\mathrm{DO}_{2}$ in the $\mathrm{Bal}$ group lasted up to $1 \mathrm{~h} 45 \mathrm{~min}: \mathrm{DO}_{2 \mathrm{Bal}(1: 45)}=713.0 \pm 53.0 \mathrm{ml} / \mathrm{min}$, $\mathrm{p}<0.05$. Starting from $1 \mathrm{~h} 50 \mathrm{~min}$ inclusive in this group, the $\mathrm{DO}_{2}$ value did not significantly differ from the initial $(\mathrm{p}>0.05)$.

A significant increase in $\mathrm{DO}_{2}$ in the NS group lasted until the 40th minute: $\mathrm{DO}_{2 \mathrm{NS}}(0: 40)=678.0 \pm$ $\pm 58.0 \mathrm{ml} / \mathrm{min}$, in the NS group at the 15 th minute $+18.70 \%$ $66.0 \mathrm{ml} / \mathrm{min}, \mathrm{p}<0.05$. Starting from the 45 th minute, inclusively, in this group, the $\mathrm{DO}_{2}$ value did not significantly differ from the initial one $(\mathrm{p}>0.05)$.

There was no significant difference between the 3 groups 45 minutes after infusion in any measurement $(\mathrm{p}>0.05)$. From 50 minutes to the second hour, a significant difference was found only between the Sorb and NS groups $(\mathrm{p}<0.05)$.

The initial $\mathrm{pH}$ level of the central venous blood (Fig. 6) did not differ ( $>0.05)$ and was 7.26 \pm 0.02 , $7.29 \pm 0.03$, and $7.31 \pm 0.02$ in Sorb, Bal, and NS groups, respectively. After 1 hour, significant increases were found in the Sorb and Bal groups, which were 7.30 \pm 0.02 and $7.32 \pm 0.02, p<0.05$ and $\mathrm{p}<0.05$. In the NS group, there was no significant change, after 1 hour the $\mathrm{pH}$ was $7.32 \pm 0.02, \mathrm{p}>0.05$. 
The initial $\mathrm{pH}$ level of the central venous blood (Fig. 6) did not differ ( $p>0.05$ ) and was 7.26 \pm 0.02 , $7.29 \pm 0.03$, and $7.31 \pm 0.02$ in Sorb, Bal, and NS groups, respectively. After 1 hour, significant increases were found in the Sorb and Bal groups, which were 7.30 \pm 0.02 and $7.32 \pm 0.02, p<0.05$ and $p<0.05$. In the NS group, there was no significant change, after 1 hour the $\mathrm{pH}$ was $7.32 \pm 0.02, \mathrm{p}>0.05$.

\section{$\mathrm{DO}_{2}(\mathrm{ml} / \mathrm{min})$}

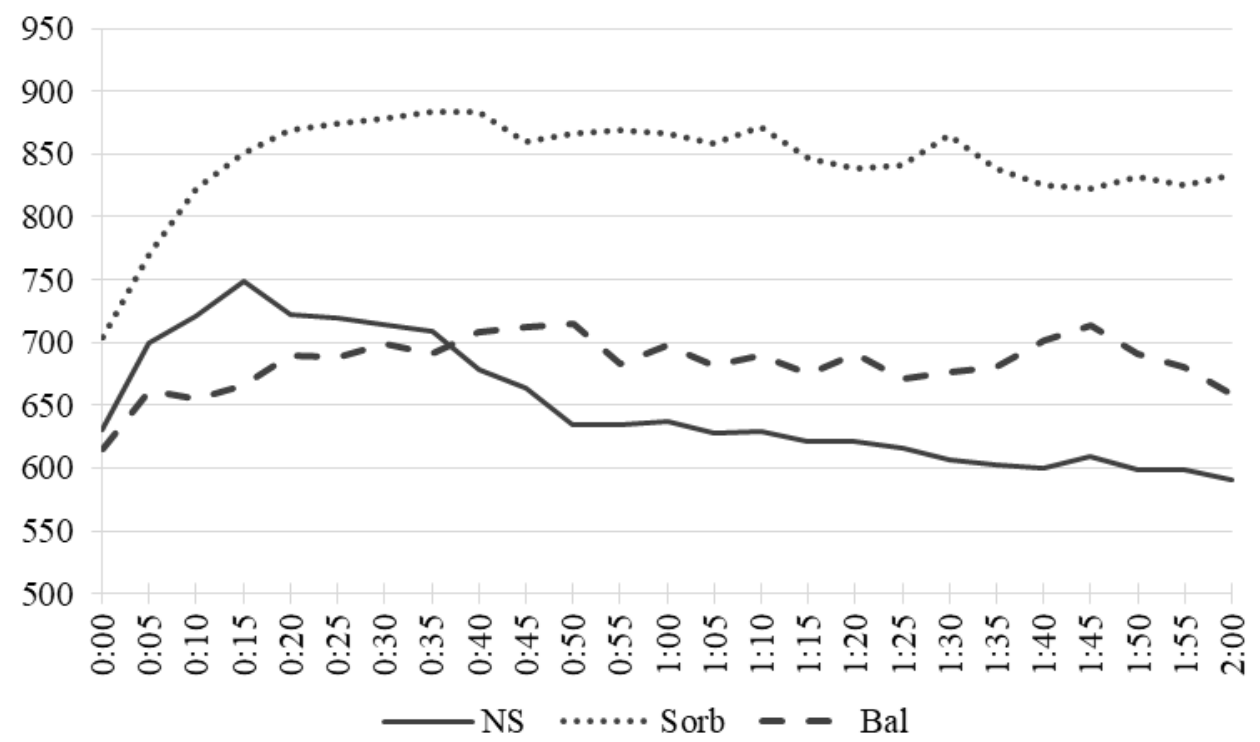

Fig. 5. Dynamics of the calculated systemic oxygen delivery with arterial blood $(\mathrm{ml} / \mathrm{min})$

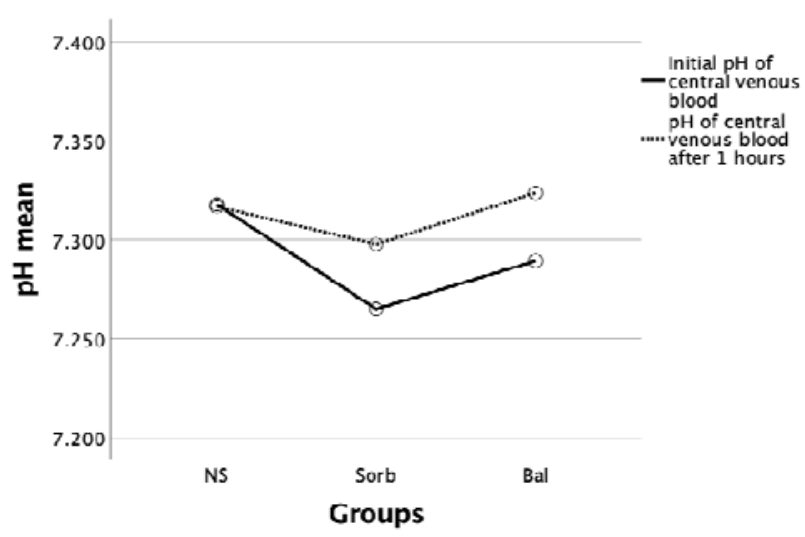

Fig. 6. Changes in $\mathrm{pH}$ levels of central venous blood

$\mathrm{ScvO}_{2}$ levels of central venous blood (Fig. 7) in the Sorb, Bal, and NS groups were $61.9 \pm 1.9 \%, 60.7 \pm$ $\pm 2.8 \%$, and $57.0 \pm 2.6 \%$, respectively $(\mathrm{p}>0.05)$. All groups showed significant increases at 1 hour after infusion, especially in the Sorb group there was a very pronounced change. The $\mathrm{ScvO}_{2}$ level in the groups became $71.2 \pm 1.8 \%, 66.7 \pm 2.9 \%$, and $63.4 \pm 2.6 \%$, respectively, $\mathrm{p}<0.001, \mathrm{p}<0.05$ and $\mathrm{p}<0.05$.

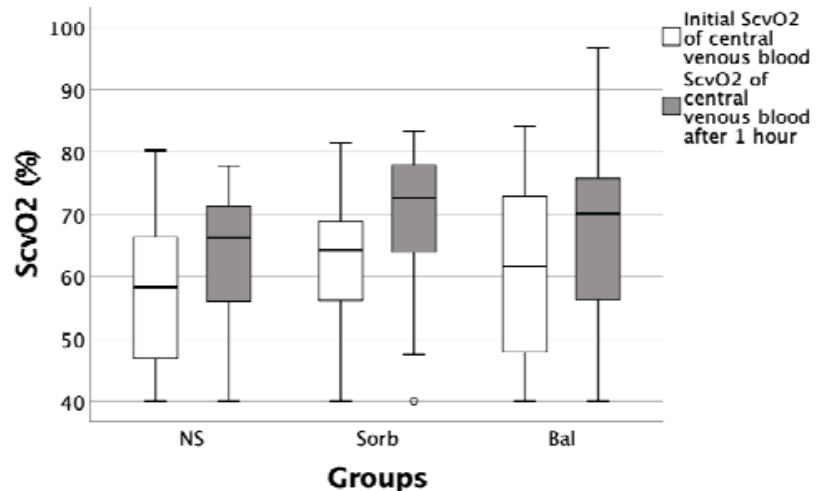

Fig. 7. Change in central venous blood of $\mathrm{ScvO}_{2}$ level ( \%)

The BE values of central venous blood (Fig. 8) did not differ before infusion ( $\mathrm{p}>0.05)$, in Sorb, Bal, and NS groups, respectively, they were $-6.51 \pm 1.12 \mathrm{mmol} / \mathrm{L}$, $-5.36 \pm 1.14 \mathrm{mmol} / \mathrm{L}$, and $-4.74 \pm 1.12 \mathrm{mmol} / \mathrm{L}$. In the Sorb and Bal groups, significant increases in levels were found 1 hour after infusion $-4.74 \pm 1.24 \mathrm{mmol} / \mathrm{L}$ and $-4.09 \pm 1.28 \mathrm{mmol} / \mathrm{L}, \mathrm{p}<0.05$. In the NS group, there was no significant change; 1 hour after the infusion, $\mathrm{BE}$ was $-4.75 \pm 1.30 \mathrm{mmol} / \mathrm{L}, \mathrm{p}>0.05$. 


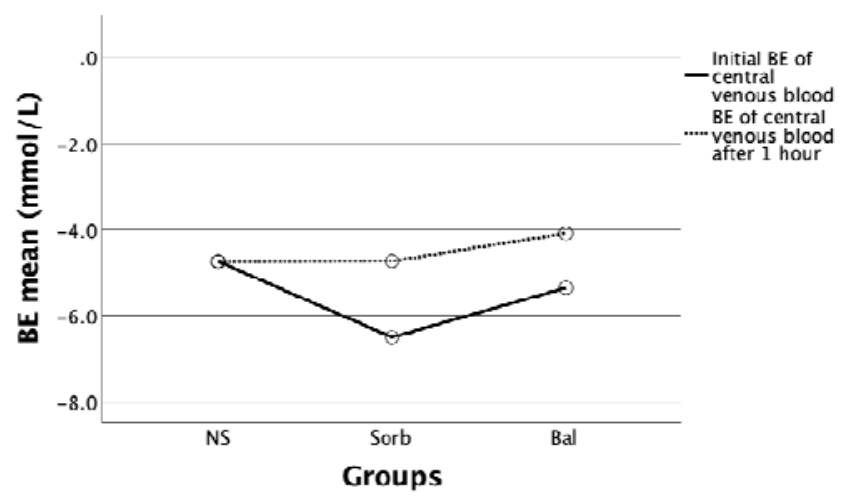

Fig. 8. Change in BE level of central venous blood $(\mathrm{mmol} / \mathrm{L})$

Baseline creatinine levels (Fig. 9) in the Sorb, $\mathrm{Bal}$, and NS group were $174 \pm 12 \mathrm{mmol} / \mathrm{L}, 165 \pm$ $\pm 19 \mathrm{mmol} / \mathrm{L}$, and $182 \pm 19 \mathrm{mmol} / \mathrm{L}$, respectively, the difference between the groups was not pronounced $(p=0.729)$. Significant changes were not found in any groups after infusion, after 24 hours, the creatinine levels became $185 \pm 11 \mathrm{mmol} / \mathrm{L}, 177 \pm 13 \mathrm{mmol} / \mathrm{L}$ and $195 \pm$ $\pm 17 \mathrm{mmol} / \mathrm{L}$, respectively $\mathrm{p}>0.05, \mathrm{p}>0.05$ and $\mathrm{p}>0.05$.

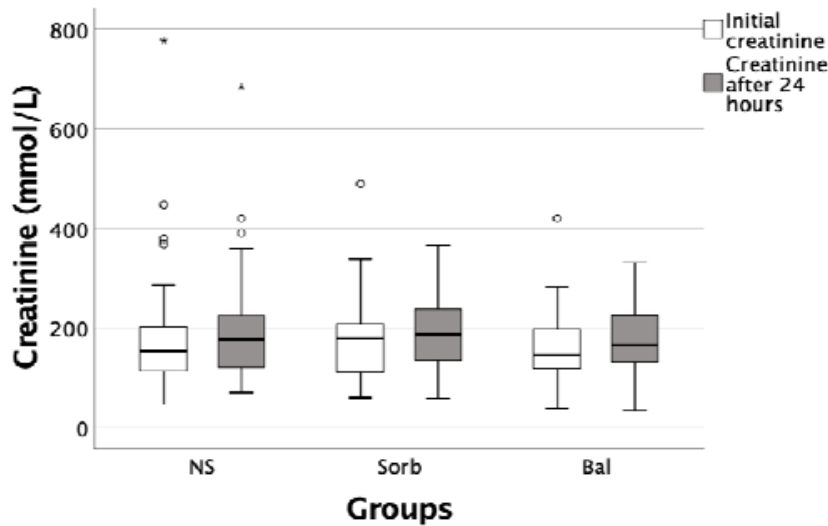

Fig. 9. Change in creatinine levels over 24 hours $(\mathrm{mmol} / \mathrm{L})$

Average PTI values are shown in Fig. 10. At the beginning of the study, the mean PTI value between all groups did not differ, in Sorb, Bal and NS group, respectively, it was $82.30 \pm 2.31 \%, \quad 78.27 \pm 0.68 \%$ and $81.71 \pm 3.07 \%, \mathrm{p}>0.05 .2$ hours after the infusion, no pronounced change was found in any of the groups, PTI became $81.70 \pm 3.72 \%, 78.55 \pm 1.11 \%$ and $81.43 \pm 4.85 \%$, $\mathrm{p}>0.05$, respectively.

Before the start of the study, aPTT indices had no statistical difference in the 3 groups (Fig. 11) and in the Sorb, Bal and NS groups, respectively, $34.00 \pm 2.94 \mathrm{~s}$, $30.83 \pm 2.63 \mathrm{~s}$ and $35.40 \pm 2.25 \mathrm{~s}, \mathrm{p}>0.05$. In all groups, no significant changes in aPTT were found 2 hours after infusion - $35.67 \pm 3.36 \mathrm{~s}, 29.33 \pm 2.49 \mathrm{~s}$, and $32.40 \pm 2.24 \mathrm{~s}$, respectively $(\mathrm{p}>0.05)$.

The amount of fibrinogen at the beginning of the study also did not differ and in the Sorb, Bal and NS groups, respectively, was $5.52 \pm 0.44 \mathrm{~g} / \mathrm{L}, 5.15 \pm 0.81 \mathrm{~g} / \mathrm{L}$ and $6.5 \pm 0.47 \mathrm{~g} / \mathrm{l}, \mathrm{p}>0.05$. The changes in the concentration of fibrinogen in the blood in any of the groups were not statistically significant. 2 hours after infusion, the fibrinogen level was $5.57 \pm 0.40 \mathrm{~g} / \mathrm{L}, 5.68 \pm 0.86 \mathrm{~g} / \mathrm{L}$, and $6.35 \pm 0.33$, respectively ( $\mathrm{p}>0.05)$.

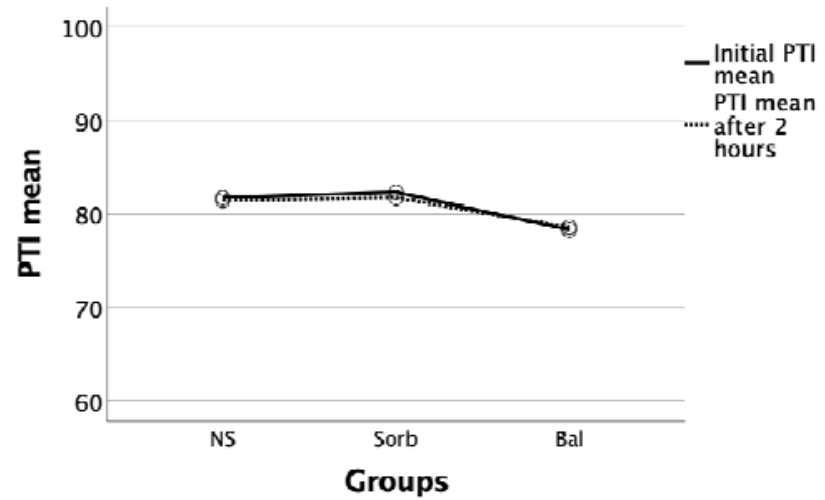

Fig. 10. PTI change (\%)

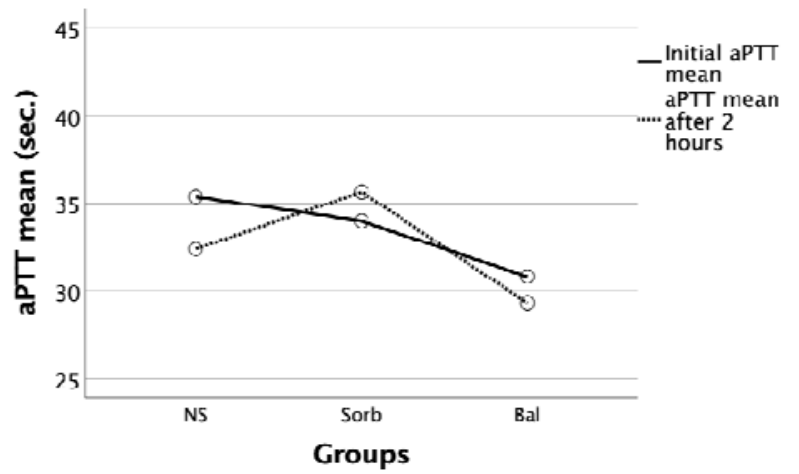

Fig. 11. aPTT change (seconds)

The average INR is shown in Table 2. At the beginning of the study, the mean INR between all groups was not statistically different, $p>0.05$. 2 hours after infusion, no significant change was found in any of the groups $(\mathrm{p}>0.05)$.

The initial platelet counts did not differ significantly (Fig. 12); in Sorb, Bal and NS groups, respectively, they were $279.0 \pm 21.0 * 10^{9} / 1,251.0 \pm 13.0 * 10^{9} / 1$ and $282.0 \pm 24.0 * 10^{9} / 1, \mathrm{p}>0.05$. A significant decrease in the number of platelets was noted in the Bal group and after 24 hours was $203.0 \pm 15.0 * 10^{9} / 1, \mathrm{p}<0.05$. No changes in platelet count in Sorb and NS groups were found, after 24 hours $-273.0 \pm 18.0 * 10^{9} / 1$ and $275.0 \pm 23.0 * 10^{9} / 1$ $(\mathrm{p}>0.05)$.

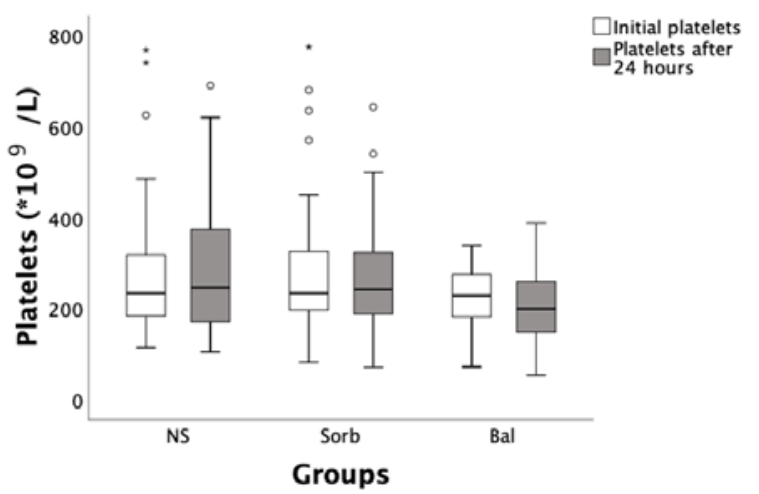

Fig. 12. Changes in platelet count one day after infusion $\left(* 10^{9} / 1\right)$ 
Table 2

INR change, $\mathrm{M} \pm \mathrm{m}$

\begin{tabular}{|c|c|c|c|}
\hline Study groups & $\begin{array}{c}\text { Sorb group } \\
\mathrm{n}=32\end{array}$ & $\begin{array}{c}\text { Bal group } \\
\mathrm{n}=29\end{array}$ & $\begin{array}{c}\text { NS group } \\
\mathrm{n}=31\end{array}$ \\
\hline Initial & $1.40 \pm 0.07$ & $1.28 \pm 0.06$ & $1.35 \pm 0.07$ \\
\hline After infusion & $1.36 \pm 0.07$ & $1.30 \pm 0.07$ & $1.31 \pm 0.07$ \\
\hline
\end{tabular}

The differences in APACHE II scores in all patients before the study were statistically insignificant (Fig. 13), in the Sorb, Bal and NS groups they were $14.64 \pm 0.87$ points, $15.25 \pm 1.09$ points and $14.43 \pm$ \pm 1.14 points, $p>0.05$. In Sorb, Bal group the tendencies of decrease of points were revealed. Average scores of Sorb, Bal and NS groups after 24 hours: 13.96 \pm \pm 1.17 points, $13.95 \pm 1.32$ points and $14.96 \pm 1.17$ points $(\mathrm{p}>0.05)$.

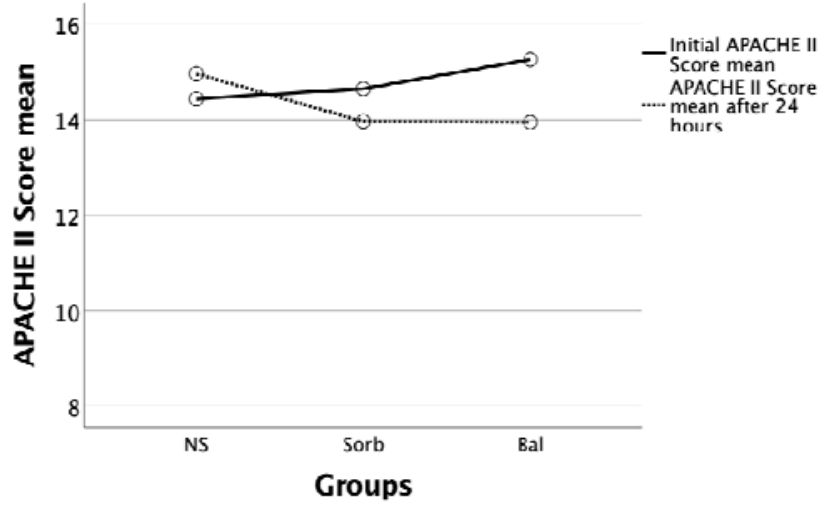

Fig. 13. APACHE II score

In Fig. 14, 15 show the ratio of patients with fatal outcome to survivors 7 and 28 days after the detection of shock. The difference in 7-day mortality between the 3 groups was not statistically significant, in the Sorb, Bal and NS groups, respectively, it was $28.1 \%$ (9 of 32), $37.9 \%$ (11 of 29 ) and $38.7 \%$ (12 of 31 ), $\mathrm{p}>0.05$. The difference in 28-day mortality between the 3 groups was also not statistically significant, in the Sorb, Bal and NS groups, respectively, it was $40.6 \%$ (13 of 32 ), $41.4 \%$ (12 of 29 ) and $45.2 \%$ (14 of 31$), \mathrm{p}>0.05$.

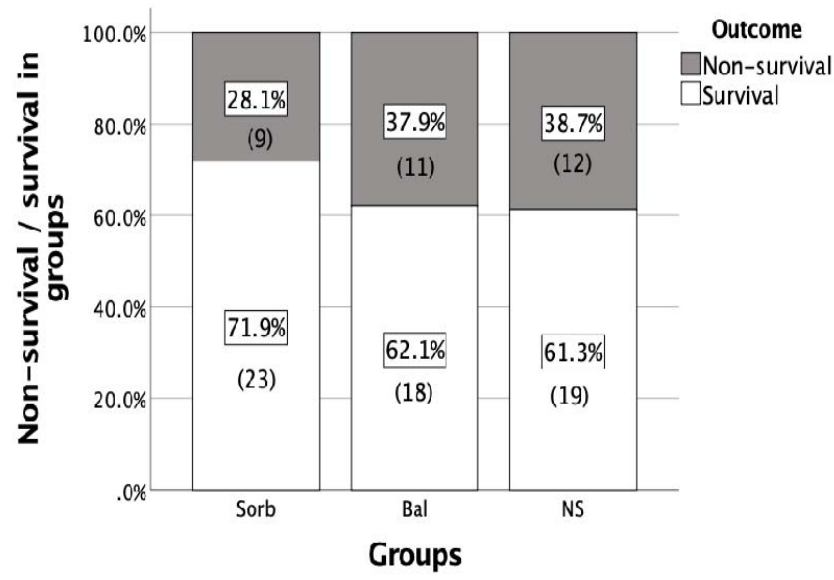

Fig. 14. The result of treatment of patients 7 days after the detection of shock

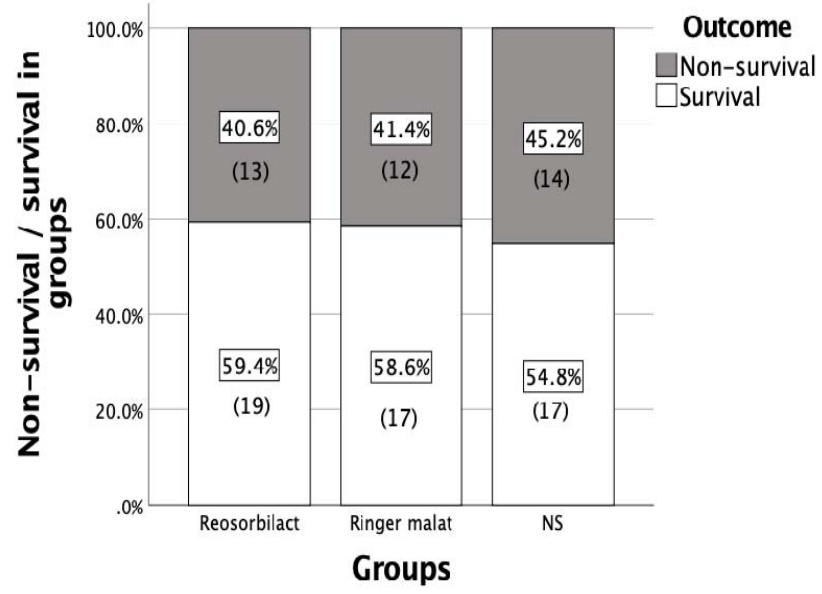

Fig. 15. The result of the treatment of patients 28 days after the detection of shock

\section{Discussion of research results}

When using the described 3 types of solutions for resuscitation of patients with septic shock in the same volume with the same injection rate, the MAP increased simultaneously and significantly, the amplitude of the increase was the same, but the duration of action was the longest when using the sorbitol-containing solution. The duration of action when using a balanced polyionic solution was in second place, the duration of action was shortest when using $0.9 \%$ sodium chloride solution. Therefore, at the 2nd hour, the MAP level in the Sorb group was significantly higher than in the NS group. $\mathrm{CO}$ and $\mathrm{DO}_{2}$ simultaneously and significantly increased immediately after infusion, but the degree of increase and duration of action were greatest when using a sorbitol-containing solution, the duration of action when using a balanced polyionic solution ranked second. These changes in hemodynamics also indirectly confirm the change in $\mathrm{ScvO}_{2}$ : there was an extremely pronounced increase in the Sorb group. In addition, when using a sorbitolcontaining solution, a pronounced reflex decrease in HR was not caused as with the other 2 drugs. This effect can probably be explained by the hyperosmolarity of the solution $(900 \mathrm{mOsm} / \mathrm{L})$, a rapid increase in preload, and, possibly, like $7.5 \% \mathrm{NaCl}$, the ability to stimulate the rapid release of catecholamines.

After the infusion of a sorbitol-containing solution and a balanced polyionic solution, the acid-base state of the blood significantly improved, which is explained by the presence of buffer compounds in these preparations.

The dose of sorbitol-containing solution used was safe for renal function and blood clotting in septic shock in this study. But it is possible that the type of balanced polyionic solution used may be associated with a decrease in the number of blood platelets. In the study [14], which was conducted with the participation of patients enrolled in the SPLIT study, fewer patients in the $0.9 \%$ saline group required blood products (red blood cells, 
fresh frozen plasma, platelets or cryoprecipitate) compared with patients in the balanced crystalloid solution group ( $18.3 \%$ versus $30.5 \%, \mathrm{p}=0.03)$.

Compared with saline sodium chloride, there is a tendency for APACHE II scores to decrease in patients in the group receiving sorbitol-containing solution and balanced polyionic solution. However, these changes were not statistically significant.

A downward trend in 7-day mortality was observed in the Sorb group, but the change was not statistically significant, which may be due to insufficient study power.

Study limitations. The study groups were not large, about 30 patients each. Before the screening and involvement of patients in the study, in addition to the research drug, they still received a certain amount of isotonic sodium chloride, which is due to the existing standards of patient management.

Prospects for further research. In the future, it is possible to increase scope of the study, study more advanced indicators of blood coagulation and renal function to compare safety.

\section{Conclusions}

In this study, a balanced polyionic solution with $1.9 \%$ sodium lactate and $6 \%$ sorbitol was the most effective and safe infusion solution for the treatment of septic shock, but it should be used in limited quantities. The balanced crystalline solution should remain as the primary drug for fluid therapy. When using a balanced polyionic solution (Ringer's acetate) with $0.07 \%$ L-malonic acid, the platelet count should be monitored more often. The use of the test solutions did not significantly affect the 7-day and 28-day mortality.

\section{Conflict of interests}

The authors declare that they have no conflicts of interest.

\section{Acknowledgments}

We would like to express my gratitude to my scientific advisor, prof. Glumcher Felix Semenovich, for the advice and assistance in conducting the research.

\section{References}

1. Rhodes, A., Evans, L. E., Alhazzani, W., Levy, M. M., Antonelli, M., Ferrer, R. et. al. (2017). Surviving Sepsis Campaign: International Guidelines for Management of Sepsis and Septic Shock: 2016. Intensive Care Medicine, 43 (3), 304-377. doi: http://doi.org/10.1007/s00134-017-4683-6

2. Simpson, N., Lamontagne, F., Shankar-Hari, M. (2017). Septic shock resuscitation in the first hour. Current Opinion in Critical Care, 23 (6), 561-566. doi: http://doi.org/10.1097/mcc.0000000000000460

3. Leisman, D., Wie, B., Doerfler, M., Bianculli, A., Ward, M. F., Akerman, M. et. al. (2016). Association of Fluid Resuscitation Initiation Within 30 Minutes of Severe Sepsis and Septic Shock Recognition With Reduced Mortality and Length of Stay. Annals of Emergency Medicine, 68 (3), 298-311. doi: http://doi.org/10.1016/j.annemergmed.2016.02.044

4. Cinel, I., Kasapoglu, U. S., Gul, F., Dellinger, R. P. (2020). The initial resuscitation of septic shock. Journal of Critical Care, 57, 108-117. doi: http://doi.org/10.1016/i.jcrc.2020.02.004

5. Tafner, P. F. do A., Chen, F. K., Rabello Filho, R., Corrêa, T. D., Chaves, R. C. de F., Serpa Neto, A. (2017). Recent advances in bedside microcirculation assessment in critically ill patients. Revista Brasileira de Terapia Intensiva, 29 (2), 238-247. doi: http://doi.org/10.5935/0103-507x.20170033

6. Nasirova, R. I., Fatullaeva, A. A. (2020). Optimization of infusion-transfusion therapy in patients with traumatic brain injury. Infusion \& Chemotherapy, 3.1, 51-52. doi: http://doi.org/10.32902/2663-0338-2020-3.1-43

7. Cherniy, V. (2015). Topical aspects of infusion therapy. Emergency medicine, 3, 43-53.

8. Parrish, D., Lindell, S. L., Reichstetter, H., Aboutanos, M., Mangino, M. J. (2016). Cell Impermeant-based Low-volume Resuscitation in Hemorrhagic Shock: A Biological Basis for Injury Involving Cell Swelling. Annals of Surgery, 263 (3), $565-572$. doi: http://doi.org/10.1097/sla.0000000000001049

9. Datsyuk, O. I. (2016). Optimization of Infusion Therapy in Preoperative Period in Patients with Acute Pancreatitis. Klinicheskaia Khirurgiia, 7, 8-10.

10. Konovchuk, V. M., Andrushchak, A. V. (2018). The effect of reosorbilact on volumetric and osmoregulatory renal functions in patients with dopamine-dependent compensation for sepsis-induced hypotension. Journal of Education, Health and Sport, 8 (2), 280-289. doi: http://doi.org/10.5281/zenodo.1186275

11. Gumeniuk, M. I., Gumeniuk, G. L., Opimakh, S. G. (2020). Anaphylactic shock infusion therapy. Infusion \& Chemotherapy, 2, 21-27. doi: http://doi.org/10.32902/2663-0338-2020-2-21-27

12. Singer, M., Deutschman, C. S., Seymour, C. W., Shankar-Hari, M., Annane, D., Bauer, M. et. al. (2016). The Third International Consensus Definitions for Sepsis and Septic Shock (Sepsis-3). JAMA, 315 (8), 801-810. doi: http://doi.org/10.1001/jama.2016.0287

13. Nguyen, H. B., Jaehne, A. K., Jayaprakash, N., Semler, M. W., Hegab, S., Yataco, A. C. et. al. (2016). Early goaldirected therapy in severe sepsis and septic shock: insights and comparisons to ProCESS, ProMISe, and ARISE. Critical Care, 20 (1). doi: http://doi.org/10.1186/s13054-016-1288-3

14. Reddy, S. K., Bailey, M. J., Beasley, R. W., Bellomo, R., Mackle, D. M., Psirides, A. J., Young, P. J. (2017). Effect of $0.9 \%$ Saline or Plasma-Lyte 148 as Crystalloid Fluid Therapy in the Intensive Care Unit on Blood Product Use and Postoperative Bleeding After Cardiac Surgery. Journal of Cardiothoracic and Vascular Anesthesia, 31 (5), 1630-1638. doi: http://doi.org/10.1053/j.jvca.2017.04.023

Received date 02.12.2020

Accepted date 28.12.2020

Published date 30.01.2021

Tinglan Zuo, Postgraduate Student, Department of Anesthesiology and Intensive Care, Bogomolets National Medical University, T. Shevchenko blvd., 13, Kyiv, Ukraine, 01601

E-mail: zuotinglan@hotmail.com

Sergey Solyarik, $\mathrm{PhD}$, Assistant, Department of Anesthesiology and Intensive Care, Bogomolets National Medical University, T. Shevchenko blvd., 13, Kyiv, Ukraine, 01601 